\title{
Erratum to: Determination of indoor humidity profile using a whole-building hygrothermal model
}

\section{Fitsum Tariku (ه), Kumar Kumaran², Paul Fazio³}

1. British Columbia Institute of Technology, 3700 Willingdon Ave., Burnaby, British Columbia, Canada, V5G 3 H2

2. National Research Council, Institute for Research in Construction, 1200 Montreal rd., Ottawa, Ontario, Canada, K1A OR6

3. Concordia University, Building, Civil and Environmental Engineering Department, 1455 de Maisonneuve Blvd. West, Montreal, Quebec, Canada, H3G 1 M8

๑) Tsinghua University Press and Springer-Verlag Berlin Heidelberg 2011

\section{Erratum to}

BUILD SIMUL (2011) 4: 61-78

DOI 10.1007/s12273-011-0031-x

The original version of this article unfortunately contained an incorrect author list. In the reference list on page 78 , instead of

Rousseau M, Manning M, Said MN, Cornick SM, Swinton MC, Kumaran MK (2007). Characterization of indoor hygrothermal conditions in houses in different northern climates. In: Prodeedings of the Thermal Performance of the Exterior Envelopes of Whole Buildings X International Conference, Clearwater Beach, USA.

It should read

Rousseau M, Manning M, Said MN, Cornick SM, Swinton MC (2007). Characterization of indoor hygrothermal conditions in houses in different northern climates. In: Proceedings of the Thermal Performance of the Exterior Envelopes of Whole Buildings X International Conference, Clearwater Beach, USA.

The online version of the original article can be found at http://dx.doi.org/10.1007/s12273-011-0031-x

E-mail: Fitsum_Tariku@bcit.ca 